\title{
The Mainstreaming of Verbally Aggressive Online Political Behaviors
}

\author{
Vincent Cicchirillo, PhD, Jay Hmielowski, PhD, and Myiah Hutchens, $\mathrm{PhD}^{2}$
}

\begin{abstract}
The purpose of this paper was to investigate the relationship between verbal aggression and uncivil media attention on political flaming. More specifically, this paper examines whether the use of uncivil media programming is associated with the perceived acceptability and intention to engage in aggressive online discussions (i.e., online political flaming) and whether this relationship varies by verbal aggression. The results show that individuals less inclined to engage in aggressive communication tactics (i.e., low in verbal aggression) become more accepting of flaming and show greater intention to flame as their attention to uncivil media increases. By contrast, those with comparatively higher levels of verbal aggression show a decrease in acceptance and intention to flame as their attention to these same media increases.
\end{abstract}

\section{Introduction}

$\mathbf{I}^{\mathrm{x}}$

NDIVIDUALS HAVE GREATER ACCESS to information than ever before, with cable news networks and the Internet providing access to political news content 24 hours a day. New technologies also allow people to discuss politics without the typical constraints associated with face-to-face communication. Web sites allow readers to become active participants in the news process by inviting them to comment on stories ${ }^{1}$ and discuss important issues with members of the online community. However, scholars have pointed out that with these technological advances people are consuming more supportive information on partisan outlets. ${ }^{2-4}$ The concern with these programs is that they contain large amounts of aggressive, uncivil discourse. ${ }^{5,6}$ The prominence of these tactics has led some to voice concern that these types of programs contribute to the increasingly partisan environment in which people perceive political opponents with disdain. ${ }^{5-9}$ Research has shown that watching uncivil programming creates a toxic political environment in which the public loses trust and respect for government institutions and leaders. ${ }^{8,9}$ Furthermore, research shows that uncivil media consumption can lead to an increase in the expression of incivility when expressing political opinions. ${ }^{10}$ This paper examines whether the use of uncivil cable TV programming increases the perceived acceptability and intention to engage in aggressive online discussions (i.e., online political flaming). Furthermore, it considers whether there is a mainstreaming effect from watching uncivil media programming on perceived acceptability and intention to engage in aggressive behaviors among those with different levels of verbal aggression.

\section{Political flaming and cultivation}

Political flaming is a concept based upon online flaming and centers on aggressive communication around politics in online spaces. Flaming has been described as "hostile and aggressive interactions via text-based computer-mediated communication." "Simply stated, flaming is a hostile message sent via an online communication channel (e.g., e-mail, instant messaging, blogging, online discussion groups, etc.). Political flaming has been shown to be a common occurrence in online spaces. ${ }^{12}$ A number of studies have found a large proportion of online comments include aggressive communication tactics. ${ }^{13}$ Indeed, up to $30 \%$ of comments on online discussion boards have been categorized as uncivil or impolite. ${ }^{14}$

One potential way that people learn that aggressive communication strategies are an acceptable way to discuss politics online is cable news. Recent content analyses showed cable news programming contains many depictions of verbal aggression. ${ }^{5}$ This research found that opinion-based news sources (e.g., cable TV, talk radio, political blogs, and newspaper columns) include significant amounts of aggressive discourse. ${ }^{5}$ Thus, research suggests that cable news can often be viewed as uncivil media programming. Therefore, it is possible that paying attention to these programs will cultivate beliefs that using aggressive language when talking politics online is acceptable behavior. According to Cultivation Theory, television

\footnotetext{
${ }^{1}$ Department of Advertising, University of Texas at Austin, Austin, Texas.

${ }^{2}$ Edward R. Murrow College of Communication, Washington State University, Pullman, Washington.
} 
may be viewed as a source of maintaining and establishing conventional standards of beliefs and behaviors. ${ }^{15}$ These beliefs can then manifest themselves in the form of perceived acceptability and intentions to engage in specific behaviors, such as negative stereotypes of women and dating perceptions. $^{16}$

Recent cultivation studies also point to relationships between greater use of television and acceptance of aggressive communication and physical behaviors. Researchers have found that heavy television use (e.g., crime dramas and soap operas) is correlated with greater acceptance of the rape myth (i.e., false accusations of rape and promiscuity). ${ }^{17}$ Some research has also shown that media content may teach young adolescents and children that the use of verbal aggression is an acceptable way to deal with rejection of intimacy from a potential relational partner. ${ }^{18}$ Researchers have also found that antisocial media consumption (i.e., media that contains violence, sex, and drug abuse) contributed to cyberbullying behaviors. ${ }^{19}$ The above-mentioned research suggests that there could be a relationship between viewing uncivil media programming and the perceived acceptability of flaming. Given the results of a recent content analysis ${ }^{5}$ that showed cable news programming contains many depictions of verbal aggression, it is possible that paying attention to these programs will cultivate beliefs that engaging in verbally aggressive behaviors is acceptable behavior, and increase the likelihood of using aggressive communication tactics when others challenge one's opinions. Thus, based on the research presented, the following hypothesis is proposed:

H1: There is a positive relationship between attention to uncivil media programs and (a) flaming acceptability and (b) intention to engage in political flaming.

\section{Mainstreaming}

A unique contribution of cultivation research is the mainstreaming hypothesis. The rationale behind mainstreaming is that heavy use of television can override differences between individuals (e.g., men vs. women, Democrats vs. Republicans). Thus, mainstreaming pushes dissimilar groups of individuals toward a middle position or a mainstreamed average. ${ }^{20}$ For example, research has found that heavy television viewing among liberals and conservatives brought them toward similar viewpoints regarding issues such as social spending, taxes, and abortion. ${ }^{21}$ Researchers have also found that adolescents with both high and low socioeconomic status (SES) held similar levels of authoritarianism when their use of media was high. ${ }^{22}$ The results of these studies ${ }^{20,21}$ show conditional effects of media use across political ideologies (e.g., liberal, moderate, and conservative) and demographic variables (e.g., age, SES, or sex). ${ }^{22}$ To examine the mainstreaming hypothesis, we have decided to look at the trait variable of verbal aggression. Since flaming is inherently an expression of aggression through verbal text, verbal aggression would be a key characteristic that predicts flaming behaviors. Past research has also used verbal aggression as an interaction variable between aggressive media exposure and the activation of aggressive thoughts. ${ }^{23}$ Thus, the present study begins by examining the potential relationship between verbal aggression and the flaming outcomes. It then moves on to examine whether people with different levels of verbal aggression move to a similar point in their beliefs about flaming the more they pay attention to uncivil media.

\section{Verbal aggression}

Overall, verbal aggression is considered a threat to civil public discourse. ${ }^{24}$ Verbal aggression is a person's tendency to attack another person's self-concept instead of attacking the person's opinion or argument. ${ }^{25}$ Studies have shown a direct relationship between verbal aggression and the perceived acceptability of using verbally aggressive tactics and intention to engage in verbally aggressive behaviors. ${ }^{26}$ Indeed, individuals who score high on aggressive personality measures were more likely to describe an ambiguous social situation with aggressive language in a sentence completion task. ${ }^{27}$ This finding occurred regardless of whether individuals had previously viewed aggressive behaviors as being negatively reinforced. Thus, regardless of positive or negative reinforcement, individuals with high trait aggression often view hostility as a reasonable course of action. As this research indicates, verbal aggression should be associated with perceived acceptability of flaming and the intention to flame when talking politics online. Accordingly, the following hypothesis was formulated:

\section{H2: There will be a positive relationship between verbal aggression and (a) flaming acceptability and (b) intention to engage in political flaming.}

While the above-formulated hypothesis is important to extend the current research in terms of main effects, the use of hostile cable programing may reduce the differences between individuals with high and low levels of verbal aggression. In essence, as people with low and high levels of verbal aggression consume uncivil media, they may hold similar views about the use of aggressive communication tactics when discussing politics online. Research has examined how specific personality traits (e.g., trait anxiety, sensation seeking, and psychoticism) moderated the cultivation effects of television use on perceptions of violence. ${ }^{28}$ This study showed that individuals who scored lower on trait anxiety and psychoticism were more likely to view society as violent as television use increased. ${ }^{28}$ The research of Nabi and Riddle suggests that greater use of television led those with high and low levels of trait anxiety to move toward a similar point on their estimates of violence in society. ${ }^{28}$ As such, individual traits may moderate the main effect of uncivil media attention. Trait verbal aggression could serve as a potentially important moderating variable between uncivil media attention and measures of aggression. For instance, it could be that individuals high in verbal aggression might experience a cathartic effect through uncivil media exposure, while those low in verbal aggression become primed with uncivil discourse. A cathartic effect occurs when individuals build up negative emotions (including aggression) that can then be released through the expression of their negative emotions. ${ }^{29}$ Furthermore, new media options such as texting, instant messaging, and video games can aid in this process by giving individuals an outlet to express negativity, thereby releasing built-up emotions. Research has found evidence that social media spaces such as instant messaging can be used to release negative emotions and/or emotional distress. ${ }^{30}$ Other research, albeit in a different media contexts (i.e., video games) 
has shown that individuals will seek out violent media for a cathartic effect. ${ }^{31}$ Thus, uncivil media attention can lead those with different levels of certain trait variables toward similar estimates of violence in society. Therefore, it is proposed that there will be an interaction in which uncivil cable news use leads people with different levels of verbal aggression to converge toward holding views about political flaming.

\section{H3: There will be a mainstreaming effect, such that greater attention to uncivil media programs leads those with high and low levels of verbal aggression to show similar levels of (a) flaming acceptability and (b) intention to engage in political flaming.}

\section{Methods}

\section{Data}

The data used to test the proposed hypotheses were obtained from a survey of political blog readers in the fall of 2011. This purposive sample was obtained by sending out invitations to moderators for the top 100 political blogs listed on Technorati.com, which indexes the most popular blogs on the Internet by category. The moderators were asked to post the link on their blogs, along with a short statement describing the purpose and scope of the survey, which was to examine Internet usage habits. Readers of blogs were surveyed because they are likely to engage in online political discussions and watch cable news. Other researchers have used this strategy of surveying blog readers in the past with success. ${ }^{32,33}$ The survey was posted on three blogs and was accessed 472 times. However, only 293 individuals completed the survey in its entirety.

\section{Independent variable}

Uncivil media attention. An index of uncivil media attention was created using participants' responses to questions asking how much attention they paid to political stories when watching partisan programs on MSNBC and Fox News (e.g., Countdown with Keith Olbermann, The Rachel Maddow Show, The Ed Show, The Last Word with Laurence O'Donnell, Hannity, The O'Reilly Factor, and On The Record with Greta VanSusteren) on a 5-point scale where $0=$ " none" and $4=$ "a great deal" $(M=0.78, S D=0.79, \alpha=0.83)$. These programs have been used in prior research to examine hostile communication tactics. ${ }^{5}$ For instance, researchers have used these types of programs when examining moral outrage and uncivil media programs (Hannity \& Countdown with Keith Olbermann). ${ }^{5}$ Attention was the focus because researchers have noted it is a better measure than using media exposure when assessing cognitive and behavioral effects. ${ }^{34,35}$ Moreover, previous studies have used attention within a cultivation framework. ${ }^{36}$

\section{Moderating variable}

Verbal aggression. To measure trait verbal aggression, ${ }^{37}$ the 10 -item verbal aggression index ${ }^{25}$ was employed using a 5-point scale where $1=$ "strongly disagree" and 5= "strongly agree" ( $M=1.98, S D=0.67, \alpha=0.87)$. Example items include statements such as "When individuals are very stubborn, I use insults to soften the stubbornness" and "If individuals I am trying to influence really deserve it, I attack their character."

\section{Dependent variables}

Flaming acceptability. Eight items were averaged together to create the measure of flaming acceptability ${ }^{12}$ on a 5-point scale ranging from $1=$ "strongly disagree" to $5=$ "strongly agree" $(M=2.11, S D=0.79, \alpha=0.91)$. Example items include statements such as "I enjoy attacking people online with whom I disagree," "It's acceptable to insult people who attack your beliefs," "It's acceptable to say aggressive things to people online when discussing politics," and "It's acceptable to say aggressive things to people who hold different opinions from your own."

Political flaming intention. Participants were asked to indicate how likely they were to respond in an aggressive manner to online comments that disagreed with their position, using a 5 -point scale ranging from $1=$ "very unlikely" to $5=$ "very likely" $(M=1.35, S D=0.56, \alpha=0.67)$. The items asked respondents how likely they were to respond with an insult, to swear at the individual, or to use all caps in the message.

\section{Control variables}

Several control variables were also included to account for the unique variance of each of these variables. Indeed, previous research has noted that some of these variables (e.g., $\operatorname{sex}^{23,38}$ ) correlate with aggressive outcomes. Therefore, the following variables were included in the regression model.

Media attention. A measure of attention to traditional media use was included in the regression models. Traditional media attention was assessed by asking individuals how much attention they pay to political stories using a 5-point scale ranging from $0=$ "none" to $4=$ "a great deal" when watching news programming on networks such as $\mathrm{ABC}$, CBS, or NBC $(M=1.23, S D=1.21)$ and when reading a newspaper, either in print or online $(M=2.97, S D=1.21)$.

Political ideology. Political ideology was measured with a single item asking participants their political ideology on a 7-point scale ranging from $1=$ "strongly liberal" to $7=$ "strongly conservative" $(M=1.85, S D=1.07)$.

Political interest. Political interest was measured with one item asking respondents how much they agreed with the statement "I am interested in politics" on a 5-point scale where $1=$ "strongly disagree" and $5=$ "strongly agree" $(M=4.70, S D=0.55)$.

Demographics. Respondents reported their age in years $(M=44.86, S D=12.51)$. Education was measured with one item that asked respondents their level of education on an 8point scale that ranged from $1=$ "less than a high school education" to $8=$ "a professional degree" $(M=5.27, S D=1.53$ [4 year college degree]). Household income was measured with one item using a 15-point scale that ranged from $<\$ 20,000$ a year to $>\$ 150,000$ a year $(M=7.61, S D=4.41[\$ 70,000$ $79,999])$. Finally, sex was measured with a single question asking respondents to report their biological sex (66.5\% male).

\section{Data analysis}

To analyze these data, a series of OLS regression models were run predicting our two dependent variables. To test the 
Table 1. Regression Predicting Flaming Outcomes

\begin{tabular}{lcc}
\hline & $\begin{array}{c}\text { Flaming } \\
\text { acceptability } \\
\text { upon entry, B }\end{array}$ & $\begin{array}{c}\text { Flaming } \\
\text { behavior } \\
\text { intention } \\
\text { upon entry, B }\end{array}$ \\
\hline Age & $0.005(0.003)$ & $0.000(0.002)$ \\
Education & $0.023(0.024)$ & $0.028(0.019)$ \\
Sex & $-0.253(0.079) * *$ & $0.020(0.060)$ \\
Income & $0.005(0.009)$ & $-0.005(0.007)$ \\
Political ideology & $-0.045(0.035)$ & $-0.008(0.027)$ \\
Political interest & $0.168(0.066) *$ & $0.075(0.051)$ \\
Network news use & $0.017(0.031)$ & $0.036(0.024)$ \\
Newspaper use & $0.011(0.037)$ & $0.031(0.028)$ \\
Verbal aggression & $0.723(0.056) * * *$ & $0.454(0.043) * * *$ \\
$R^{2}$ & $0.421 * * *$ & $0.311 * * *$ \\
Uncivil media use & $-0.060(0.052)$ & $0.010(0.040)$ \\
$\Delta R^{2}$ & 0.001 & 0.000 \\
Verb aggression & $-0.156(0.073) *$ & $-0.163(0.056) * *$ \\
$\quad$ by uncivil & & \\
$\quad$ media use & $0.009 *$ & $0.020 * *$ \\
$\Delta \mathrm{R}^{2}$ & $0.433 * * *$ & $0.330 * * *$ \\
$\mathrm{R}^{2}$ & $0.411 * * *$ & $0.304 * * *$ \\
Adj $\mathrm{R}^{2}$ & & \\
\hline
\end{tabular}

Note: Regression coefficients are unstandardized with standard errors in parentheses. The $F$ test for the flaming acceptability model and the behavioral intention models were significant. Acceptability $=F(11,296)=23.182, p<0.001 ;$ Intention $=F(11,294)=14.268$, $p<0.001$.

$* p<0.05 ; * * p<0.01 ; * * * p<0.001$.

interaction hypotheses, a moderated multiple regression was run. To do so, a media use by verbal aggression term was created and that interaction term was entered into the regression models, which included all controls and main effect variables (see Table 1).

\section{Results}

Hypotheses $1 \mathrm{a}$ and $1 \mathrm{~b}$ examined the relationship between uncivil media attention and flaming acceptability and political flaming intentions. These hypotheses were not supported. The results show that there is no relationship between attention to partisan media outlets and flaming acceptability $(B=-0.060$, $S E=0.052, p>0.05)$ or intention to flame $(B=0.010, S E=$
$0.040, p>0.05)$. However, the analysis does support hypotheses $2 \mathrm{a}$ and $2 \mathrm{~b}$. Specifically, the analysis shows that higher verbal aggression was associated with people believing that flaming is an acceptable behavior $(B=0.723, S E=0.056$, $p<0.05)$ and associated with greater intention to engage in political flaming $(B=0.454, S E=0.043, p<0.05)$.

Next, Hypotheses $3 \mathrm{a}$ and $3 \mathrm{~b}$ were examined, which predicted a mainstreaming effect of television use on flaming acceptability and flaming intentions. The results show support for both of these hypotheses. Specifically, the analysis shows a statistically significant verbal aggression by media attention interaction in the predicted direction for Hypothesis $3 \mathrm{a}(B=$ $-0.156, S E=0.073, p<0.05$; see Fig. 1). The graphed interaction in Figure 1 indicates that at low levels of uncivil media attention, high levels of verbal aggression are associated with greater acceptance for political flaming, while those individuals with low levels of verbal aggression show less acceptance for political flaming. However, as people consume uncivil media, their views on the acceptability of political flaming converge. Specifically, those with high levels of verbal aggression show lower levels of acceptance for political flaming as their attention of uncivil media increases. By contrast, those with low levels of verbal aggression show higher levels of acceptance for political flaming as their attention of uncivil media increases. The results also showed a significant interaction for flaming intentions, which supports Hypothesis $3 b(B=-0.163, S E=0.056, p<0.01)$. The results indicate that higher levels of verbal aggression are associated with greater intention to engage in political flaming, while those individuals with low levels of verbal aggression show lower levels of intention to engage in political flaming. As the graphed interaction shows (see Fig. 2), consuming uncivil media leads individuals with different levels of verbal aggression to converge to a similar point. Those with high levels of verbal aggression show lower levels of intention to flame as their attention to uncivil media increases. By contrast, those with low levels of verbal aggression show an increase in their intention to engage in political flaming as their use of uncivil media increases.

\section{Discussion}

This study examined the relationship between attention to uncivil political media and both perceived acceptability of and intention to engage in political flaming. The results
FIG. 1. Uncivil media use by verbal aggression interaction predicting flaming acceptability.

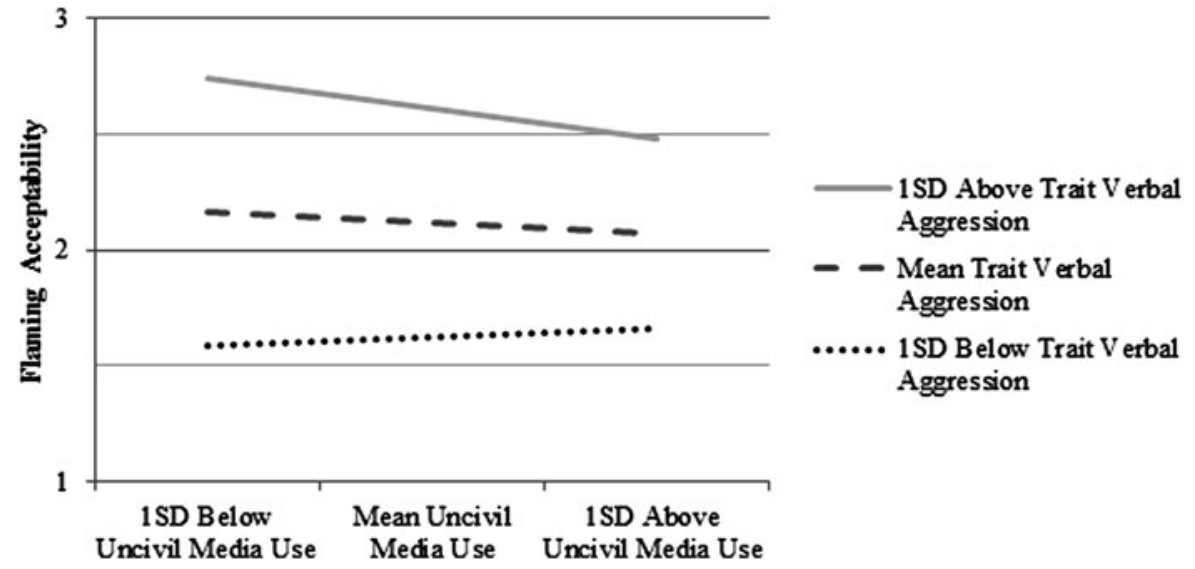




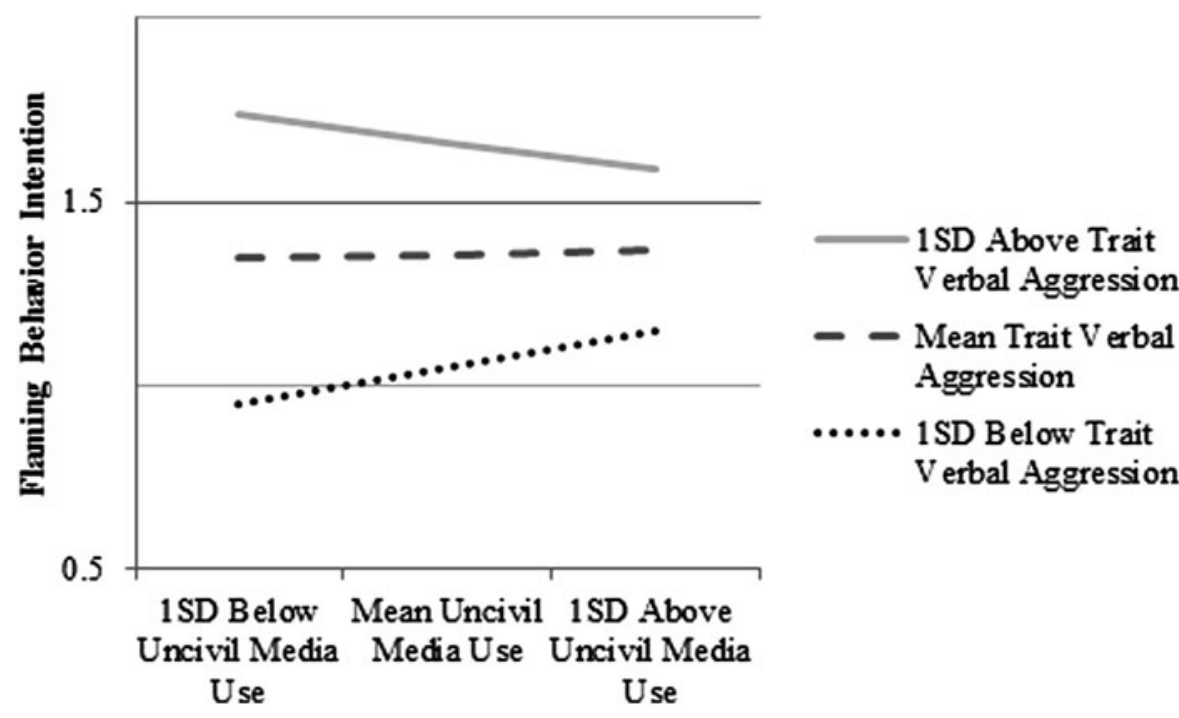

FIG. 2. Uncivil media use by verbal aggression interaction predicting flaming intention. showed no direct relationship between paying attention to uncivil media and political flaming acceptability or flaming intentions. The results did show that there is a strong relationship between verbal aggression and both of the flaming outcome variables. The analysis also found a convergent uncivil media attention by verbal aggression interaction. The findings demonstrate that people with different levels of verbal aggression converge to a similar point on both the flaming outcome variables as their use of uncivil media increases. This pattern of results supports the proposed mainstreaming hypotheses, which posited that individuals high and low in trait verbal aggression would have similar views on the acceptability of flaming and intention to flame, as they consume more uncivil media. One way to explain this interaction could be through a cathartic effect. It could be that those individuals high in verbal aggression experienced a cathartic effect as a result of viewing uncivil media, while those individuals low in trait verbal aggression were primed with aggressive tactics over time. Thus, increased viewing of uncivil media primed them with associations of political discussion and verbal aggression.

The findings of this study apply to the democratic norms of political discussion. The idealized goal of democratic theorists is to have people engage in lengthy civil discussions that result in the best possible decision. ${ }^{39,40}$ A general concern about uncivil content is the nefarious effect it has on levels of institutional trust ${ }^{8}$ and political engagement, ${ }^{9,10}$ which would be harmful to the political process and counter to the ideals of democracy. These findings provide more nuance to the potential negative effects of uncivil media on politics, and suggest that exposure to uncivil media does not have a uniform negative impact on citizens. The findings show that these relationships between uncivil media and flaming acceptability and intentions differ based on verbal aggression. These results are similar to previous research showing the conditional effects of media based on individual-level variables. ${ }^{41,42}$ Previous research has shown that SES moderates the effects of horse race coverage on people's level of political cynicism ${ }^{41}$ and the effects of news use on knowledge. ${ }^{42}$

Overall, the findings highlight the importance of looking beyond the main effects of media use. Given that the results show aggressive media may decrease aggressive behaviors among individuals most likely to use aggressive verbal tactics (i.e., those high in verbal aggression), it is possible that more civil debates on cable news, and the media more generally, would further reduce aggression among frequent viewers of political media outlets. However, results showing that media use increases aggressive tendencies among those with lower levels of verbal aggression signifies reason for concern. Civil discourse may help to curb political flaming by reducing the extent to which flaming occurs in online spaces centered around politics.

\section{Future Directions and Limitations}

Future studies should consider experimental design in order to test how civil media discourse affects verbal aggression and actual flaming behaviors. The confines of an experiment would also allow for a better assessment of whether these different types of media (i.e., civil or uncivil) cause changes in verbally aggressive outcome variables (i.e., flaming). Future studies could also look toward Social Identity Theory to examine potential differences in flaming behaviors toward ingroup and outgroup members. In essence, rewarding attacks on an outgroup could reinforce the acceptability of flaming for those who hold opposing views. Moreover, this effect could increase among those who regard membership in a particular group as central to their identity. Finally, researchers should specifically include name-calling as an index measure of political flaming. Research has indicated that name-calling is common occurrence of uncivil discourse online. ${ }^{43}$

Despite the contribution of the present study, some limitations may have affected the results. Foremost, the study uses a purposive sample, which prevents the results from being generalized to the larger population. It was felt necessary to survey frequent consumers of political information via the Internet. However, the sample is not representative of the larger population, which decreases the extent to which it can be said that these results apply to the wider U.S. population. Thus, future research should examine demographic groups related to sex and political ideology that are more representative of the population. 
Second, relying on blogs to post the survey contributed to the sample being more liberal than the populations of the typical consumer of online political content. One reason for the lack of participation among conservative bloggers could be conservatives' lack of trust in academia. ${ }^{44}$ In fact, certain academics have even gone as far as stating outright hatred for the conservative right. ${ }^{45}$ Overall, this could explain why conservatives do not trust academic institutions. Another weakness of this study is the use of cross-sectional data. Using this type of data prevents any causal claims being made about media use and the measures of flaming acceptability and intention. This issue could be dealt with using experimental methods or collecting multiple waves of survey data.

\section{Author Disclosure Statement}

No competing financial interests exist.

\section{References}

1. McCluskey M, Hmielowski JD. Opinion expression during social conflict: comparing online reader comments and letters to editors. Journalism: Theory, Practice \& Criticism 2011; 13:303-319.

2. Bennett WL, Iyengar S. A new era of minimal effects? The changing foundations of political communication. Journal of Communication 2008; 58:707-731.

3. Stroud NJ. (2011) Niche news: the politics of news choice. New York: Oxford University Press.

4. Wicks RH, Wicks JL, Morimoto SA. Partisan media selective exposure during the 2012 presidential election. American Behavioral Scientist 2014; 58:1131-1143.

5. Sobieraj S, Berry JM. From incivility to outrage: political discourse in blogs, talk radio, and cable news. Political Communication 2011; 28:19-41.

6. Anderson AA, Brossard D, Scheufele DA, et al. The "nasty effect": online incivility and risk perceptions of emerging technologies. Journal of Computer Mediated Communication 2014; 19:373-387.

7. Moy P, Pfau M. (2000) With malice toward all? The media and public confidence in democratic institutions. Westport, CT: Greenwood Press.

8. Mutz DC, Reeves B. The new video malaise: effects of television incivility on political trust. Political Science Review 2005; 99:1-15.

9. Mutz DC. "In-your-face" television discourse on perceptions of legitimate opposition. The American Political Science Review 2007; 104:621-635.

10. Gervais BT. Following the news? Reception of uncivil partisan media and the use of incivility in political expression. Political Communication 2014; 31:564-583.

11. O'Sullivan PB, Flanagin AJ. Reconceptualizing "flaming" and other problematic messages. New Media \& Society 2003; 5:69-94.

12. Hutchens M, Cicchirillo V, Hmielowski J. HOW COULD YOU THINK THAT!?!? Understanding intentions to engage in political flaming. New Media \& Society 2014; 16:1-9.

13. Rosenberry J. Users support online anonymity despite increasing negativity. Newspaper Research Journal 2011; 32:6-19.

14. Papacharissi Z. Democracy online: civility, politeness, and the democratic potential of online political discussion groups. New Media \& Society 2004; 6:259-283.
15. Gerbner G, Gross L. Living with television: the violence profile. Journal of Communication 1976; 26:173-199.

16. Ferris A, Smith SW, Greenberg BS, et al. The content of reality dating shows and viewer perceptions of dating. Journal of Communication 2007; 57:490-510.

17. Kahlor L, Eastin MS. Television's role in the culture of violence toward women: a study of television viewing and the cultivation of rape myth acceptance in the United States. Journal of Broadcasting \& Electronic Media 2011; 55:215-231.

18. Cvancara K, Kinney T. (2008) Televised social models and verbal aggression. Paper presented at the annual conference of the International Communication Association, Montreal, Canada.

19. de Hamer A, Konijn EA, Keijer MG. Cyberbullying behavior and adolescents' use of media with antisocial content: a cyclic process model. Cyberpsychology, Behavior, \& Social Networking 2014; 17:74-81.

20. Shanahan J, Morgan M. (1999) Television and its viewers: cultivation theory and research. New York: Cambridge University Press.

21. Gerbner G, Gross L, Morgan M, et al. Charting the mainstream: television's contributions to political orientations. Journal of Communication 1982; 32:100-127.

22. Shanahan J. Television and authoritarianism: exploring the concept of mainstreaming. Political Communication 1998; 15:483-495.

23. Chory-Assad RM. The effects of television sitcom exposure on accessibility of verbally aggressive. Western Journal of Communication 2004; 68:431-453.

24. Hamilton M. Verbal aggression: understanding the psychological antecedents and social consequences. Journal of Language \& Social Psychology 2012; 31:5-12.

25. Infante DA, Wigley CJ. Verbal aggressiveness: an interpersonal model and measure. Communication Monographs 1986; 53:61-69.

26. Bond AJ, Bauer A, Wingrove J. Outcome of aggression affects processing and can legitimise subsequent aggression: influence of trait aggressiveness. Aggressive Behavior 2004; 30:284-297.

27. Dill KE, Anderson CA, Anderson KB, et al. Effects of aggressive personality on social expectations and social perceptions. Journal of Research in Personality 1997; 31:272-292.

28. Nabi RL, Riddle K. Personality traits, television viewing, and the cultivation effect. Journal of Broadcasting \& Electronic Media 2008; 52:327-348.

29. Bohart AC. Toward a cognitive theory of catharsis. Psychotherapy: Theory, Research \& Practice 1980; 17:192-201.

30. Dolev-Cohen M, Barak A. Adolescents' use of Instant Messaging as a means of emotional relief. Computers in Human Behavior 2013; 29:58-63.

31. Ferguson CJ, Olson CK, Kutner LA, et al. Violent video games, catharsis seeking, bullying, and delinquency: a multivariate analysis of effects. Crime \& Delinquency 2014; 60:764-784.

32. Johnson TJ, Kaye BK. In blog we trust? Deciphering credibility of components of the Internet among politically interested Internet users. Computers in Human Behavior 2009; 25:175-182.

33. Kaye BK, Johnson TJ. Hot diggity blog: a cluster analysis examining motivations and other factors for why people judge different types of blogs as credible. Mass Communication \& Society $2011 ; 14: 236-263$.

34. Drew D, Weaver D. Media attention, media exposure, and media effects. Journalism Quarterly 1990; 67:740-748. 
35. Chaffee S, Schleuder J. Measurement and effects of attention to media news. Human Communication Research 1986; 13:76-107.

36. Reber B, Chang Y. Assessing cultivation theory and public health model for crime reporting. Newspaper Research Journal 2000; 21:99-112.

37. Wilson SR, Roberts F, Rack JJ, et al. Mothers' trait verbal aggressiveness as a predictor of maternal and child behavior during playtime interactions. Human Communication Research 2008; 34:392-422.

38. Alonzo M, Aiken M. Flaming in electronic communication. Decision Support System 2004; 36:205-213.

39. Gastil J, Dillard JP. Increasing political sophistication through public deliberation. Political Communication 1999; 16:3-23.

40. Goodin RE, Niemeyer SJ. When does deliberation begin? Internal reflection versus public discussion in deliberative democracy. Political Studies 2003; 51:627-649.

41. Valentino NA, Beckmann MN, Buhr TA. A spiral of cynicism for some: the contingent effects of campaign news frames on participation and confidence in government. Political Communication 2001; 18:347-367.
42. Tichenor PJ, Donohue GA, Olien CN. Mass media flow and differential growth in knowledge. The Public Opinion Quarterly 1970; 34:159-170.

43. Coe K, Kenski K, Rains SA. Online and Uncivil? Patterns and determinants of incivility in newspaper website comments. Journal of Communication 2014; 64:658-679.

44. MacCoun RJ, Paletz S. (2009). Citizens' perceptions of ideological bias in research on public policy controversies. Political Psychology 2009; 30:43-65.

45. Douglas SJ. (2014) We can't just get along: in our era of polarization, one party is guiltier than the other. www.inthesetimes .com (accessed Jan. 15, 2015).

Address correspondence to: Dr. Vincent Cicchirillo Department of Advertising University of Texas at Austin 300 W. Dean Keeton (A1200) Austin, TX 78712

E-mail: v.cicchirillo@mail.utexas.edu 